\title{
Comparison between Focused Electron/Ion Beam-Induced Deposition at Room Temperature and under Cryogenic Conditions
}

\author{
José María De Teresa ${ }^{1,2, * \mathbb{D}}$, Pablo Orús ${ }^{1}$, Rosa Córdoba ${ }^{3}$ and Patrick Philipp ${ }^{4}$ (D) \\ 1 Instituto de Ciencia de Materiales de Aragón (ICMA, CSIC-Universidad de Zaragoza) and Departamento de \\ Física de la Materia Condensada, Facultad de Ciencias, Universidad de Zaragoza, Calle Pedro Cerbuna 12, \\ 50009 Zaragoza, Spain; porus@unizar.es \\ 2 Laboratorio de Microscopías Avanzadas (LMA), Instituto de Nanociencia de Aragón (INA), Edificio de I+D, \\ Campus Río Ebro, 50018 Zaragoza, Spain \\ 3 Instituto de Ciencia Molecular, Universitat de València, Catedrático José Beltrán 2, 46980, Paterna, Spain; \\ rosa.cordoba.castillo@gmail.com \\ 4 Advanced Instrumentation for Ion Nano-Analytics (AINA), MRT Department, \\ Luxembourg Institute of Science and Technology (LIST), 41 rue du Brill, L-4422 Belvaux, Luxembourg; \\ patrick.philipp@list.lu \\ * Correspondence: deteresa@unizar.es
}

Received: 22 October 2019; Accepted: 18 November 2019; Published: 21 November 2019

\begin{abstract}
In this contribution, we compare the performance of Focused Electron Beam-induced Deposition (FEBID) and Focused Ion Beam-induced Deposition (FIBID) at room temperature and under cryogenic conditions (the prefix "Cryo" is used here for cryogenic). Under cryogenic conditions, the precursor material condensates on the substrate, forming a layer that is several $\mathrm{nm}$ thick. Its subsequent exposure to a focused electron or ion beam and posterior heating to $50{ }^{\circ} \mathrm{C}$ reveals the deposit. Due to the extremely low charge dose required, Cryo-FEBID and Cryo-FIBID are found to excel in terms of growth rate, which is typically a few hundred/thousand times higher than room-temperature deposition. Cryo-FIBID using the $\mathrm{W}(\mathrm{CO})_{6}$ precursor has demonstrated the growth of metallic deposits, with resistivity not far from the corresponding deposits grown at room temperature. This paves the way for its application in circuit edit and the fast and direct growth of micro/nano-electrical contacts with decreased ion damage. The last part of the contribution is dedicated to the comparison of these techniques with other charge-based lithography techniques in terms of the charge dose required and process complexity. The comparison indicates that Cryo-FIBID is very competitive and shows great potential for future lithography developments.
\end{abstract}

Keywords: focused ion beam; focused electron beam-induced deposition; focused ion beam-induced deposition; lithography; circuit edit; electrical contacts; thin films; nanowires

\section{Introduction}

Lithography techniques are at the core of technological developments in fields such as nanoelectronics, data storage, sensors, telecommunication devices, quantum technologies, etc. [1]. Despite the fact that optical lithography is the most common technique for micro/nano-patterning, various niches exist for the application of other lithography techniques. In this context, charged-particle-based lithography techniques present some advantages compared to optical lithography, such as the affordable cost for sub-100-nm resolution and the capability for fast device prototyping. Amongst them, electron beam lithography (EBL) is the most popular, with patterning resolution down to a few $\mathrm{nm}$ using a scanning electron microscope (SEM) [2]. However, EBL is a 
multi-step process using electron-sensitive resists and requires long exposure times, which limits its applicability compared to optical lithography. Focused ion beam (FIB) is also a slow processing technique but is capable of direct material removal with a resolution of a few $\mathrm{nm}$ and without the need of resists [3,4]. This is why FIB milling has become the lithography of choice in various applications requiring local material removal, such as the circuit editing of semiconductor devices [5] and materials analysis in industrial and research laboratories for the preparation of cross-sections for scanning [6] and transmission electron microscopy [7].

\section{Focused Electron/Ion Beam-Induced Deposition Techniques}

If an SEM or a FIB is combined with a precursor gas, delivered by means of a gas injector and adsorbed on the substrate, precursor dissociation will occur after electron or ion impact on the surface, giving rise to the growth of a deposit. The corresponding techniques are known as FEBID (Focused Electron Beam-induced Deposition) and FIBID (Focused Ion Beam-induced Deposition), respectively. In the past, various review articles have been devoted to the detailed description of the phenomena involved in room-temperature (RT) FEBID and FIBID processes, and the reader is referred to these references for their comprehensive understanding [8-13]. Here, we provide a view that is simplified but sufficient to understand the main differences between the RT and the cryogenic processes.

In short, in FEBID, the process is commonly described through the time-variation of the precursor adsorbate density, which depends on four terms: adsorption, desorption, diffusion and dissociation. Each of these terms is characterized by the corresponding temperature-dependent coefficient. The growth volume can be obtained from the time integration of the dissociation term and the adsorbate density. Two extreme growth regimes can occur: in the electron-limited regime the growth rate depends linearly on the electron beam current or the electron dwell time, whereas, in the precursor-limited regime the growth rate saturates beyond a certain electron beam current or electron dwell time due to the lack of precursor replenishment in the area of growth. Microscopically, all types of electrons (primary, forward-scattered, back-scattered, type-I secondary and type-II secondary) can potentially contribute to the precursor dissociation depending on the working conditions, as previously discussed in great detail in references 8 to 13 and others [14-17]. In general, the primary, forward-scattered and back-scattered electrons only dissociate a reduced amount of precursor molecules given the large difference in energy of the impacting electron (up to tens of $\mathrm{keV}$ ) and the precursor molecule bond energies (a few eV). A greater contribution to precursor dissociation comes from type-I and type-II secondary electrons, produced in the substrate and in the growing structure. The secondary electrons, with typical energies in the range of a few eV, have a higher probability of precursor bond-breaking. Temperature plays a fundamental role, owing to the large thermal dependence of important process parameters such as the diffusion coefficient and the residence time of the precursor on the surface.

On the other hand, in FIBID, the material growth has to compete with FIB milling, with both phenomena occurring simultaneously [18]. As a consequence, in the first approximation, the growth rate is given by the subtraction of the milling rate from the precursor dissociation rate. FIB milling can be reduced by the use of low ion beam currents [19]. An advantage of FIBID compared to FEBID is that each impacting ion triggers physical processes on the substrate that produce a large amount of secondary electrons on the substrate surface. As a consequence, for a given beam current and accelerating voltage, the growth rate is typically a factor of 100 higher in FIBID compared to FEBID [20]. For the growth of metallic deposits, FIBID will generally give rise to higher metal content and lower resistivity [20], which is an obvious advantage in certain applications. However, in sharp contrast with FEBID, FIBID causes substantial beam-induced damage on the substrate (amorphization, implantation, defects, etc.), which can be detrimental in some cases [21-24].

In Figure 1, various applications of FEBID and FIBID are sketched: the growth of in-plane and three-dimensional nanostructures on flat substrates [25], as well as on unconventional substrates such as cantilevers/tips [26], and flexible [27], insulating [28] or origami substrates [28], etc. Materials grown by FEBID/FIBID are currently used for circuit edit and mask repair in the semiconductor 
industry [24,29-31], lamellae preparation [7], the placement of electrical contacts to micro- and nano-structures [32,33], for producing sensors [34,35] and magnetic tips [36-38], plasmonic [39-42] and nano-optical elements [43], superconducting films [44] and nanowires [45], etc. Although FEBID/FIBID is an active field of research and development, a wider impact is hampered by the limited process speed. For example, the growth of Pt-C deposits (the most popular one) by FEBID, using the $\left(\mathrm{CH}_{3}\right)_{3} \mathrm{Pt}\left(\mathrm{C}_{\mathrm{p}} \mathrm{CH}_{3}\right)$ precursor, shows a volume per dose of $0.005 \mu \mathrm{m}^{3} / \mathrm{nC}$ under $30 \mathrm{kV}$, increasing to around $0.7 \mu \mathrm{m}^{3} / \mathrm{nC}$ for Pt-C deposits by FIBID [20]. This amounts to long processing times, especially for FEBID. As an example, a $10 \mu \mathrm{m} \times 10 \mu \mathrm{m}$ Pt-C square of $0.1 \mu \mathrm{m}$ thickness (total volume of $10 \mu \mathrm{m}^{3}$ ) grown using $1 \mathrm{nA}$ beam current requires $14 \mathrm{~s}$ using FIBID and more than half an hour using FEBID. The situation is even worse with other popular precursors such as $\mathrm{W}(\mathrm{CO})_{6}$, with values of volume per dose that are several orders of magnitude smaller than for the Pt precursor.
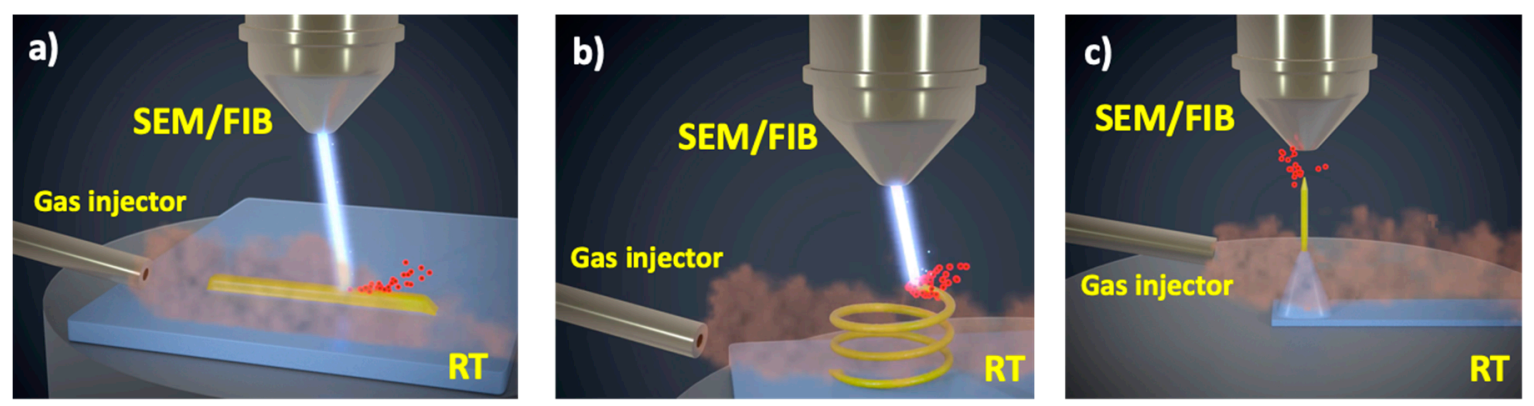

Figure 1. Three different applications of Focused Electron Beam-Induced Deposition (FEBID) and Focused Ion Beam-induced Deposition (FIBID) growth are sketched: (a) In-plane nanowires on flat substrates; (b) Three-dimensional nanostructures; (c) Nanowire growth on tips and cantilevers. RT stands for room temperature.

\section{Focused Electron/Ion Beam-Induced Deposition Techniques under Cryogenic Conditions (Cryo-FEBID and Cryo-FIBID)}

In the recent past, various lithography processes under cryogenic conditions have been developed. For example, processes based on water ice and organic ice have been carried out [46-48]. Here, the ice plays the role of the resist in Electron Beam Lithography (EBL), with the advantage that the unexposed ice becomes volatile when heating up to room temperature, instead of requiring a resist solver as in EBL. So far, the main bottleneck of this technology is the high charge dose required to expose the ice, as well as the need for subsequent steps, such as metal coating and lift-off for the fabrication of a functional nano-patterned material. On the other hand, during FIB milling, cryogenic temperatures have been found useful in order to retain the microstructure of sensitive materials for subsequent scanning and transmission electron microscopy imaging [49,50]. Also, in gas-assisted focused electron beam-induced etching, cryogenic temperatures (Cryo-FEBIE) have been found to increase the etching rate by enhancing the residence time of the etching gas [51]. Regarding deposition techniques, thin Sn films were grown under cryogenic temperatures using a condensed layer of an $\mathrm{Sn}$ precursor after exposure to a broad $\mathrm{Ar}^{+}$beam, but good lateral resolution was not attempted [52].

The first example of direct growth of a nanopatterned material by cryogenic focused beam-induced deposition techniques was reported by Bresin et al. using the $\left(\mathrm{CH}_{3}\right)_{3} \mathrm{Pt}\left(\mathrm{C}_{\mathrm{p}} \mathrm{CH}_{3}\right)$ precursor and electron irradiation, known as Cryo-FEBID [53,54]. The second example was reported by Córdoba et al. using the $\mathrm{W}(\mathrm{CO})_{6}$ precursor and ion irradiation, known as Cryo-FIBID [55]. Figure 2 illustrates the steps involved in such a process. The first step involves cooling the substrate below the condensation temperature of the precursor and opening the Gas Injection System (GIS) for a given time to allow the formation of a precursor condensation layer. The thickness of such a condensed layer is very important, as will be discussed later, and can be controlled by several means, such as the GIS valve opening time, the precursor temperature inside the GIS, and the distance between the GIS and the substrate. The second step implies the focused beam irradiation, with the obvious advantage over the 
RT process that the required irradiation dose is much smaller. As the condensed layer contains many precursor molecules available for dissociation compared to the sub-monolayer precursor layer at RT, the irradiation process is much faster. The parameters to be controlled during the irradiation process are the usual ones in FEBID/FIBID: beam current, beam voltage, scan type, dwell time, pitch, etc. Once the optimal irradiation dose has been determined, the next step to control is the heating. In this step, the non-irradiated part of the condensed layer will become volatile and only the irradiated part of the condensed layer will remain. Heating to temperatures slightly above RT, for example at $50{ }^{\circ} \mathrm{C}$ for a few minutes, has been found suitable in this step. Then the sample can be brought back to RT for further processing.
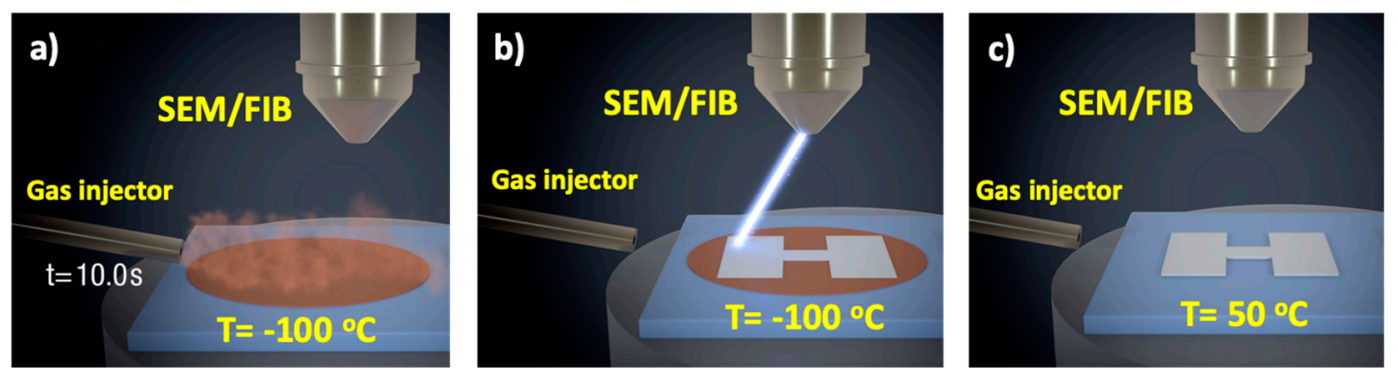

Figure 2. The three main steps of FEBID and FIBID under cryogenic conditions are sketched: (a) The precursor is dosed for a given time on a cooled substrate, giving rise to a condensed layer of precursor; (b) The focused electron or ion beam irradiates the precursor condensed layer with the wanted pattern; (c) The substrate is heated to above room temperature, which produces the sublimation of the unirradiated precursor and the emergence of the desired deposit.

\subsection{Pt-C Deposits Grown by Cryo-FEBID}

Bresin et al. have used layers of $\left(\mathrm{CH}_{3}\right)_{3} \mathrm{Pt}\left(\mathrm{C}_{\mathrm{p}} \mathrm{CH}_{3}\right)$ precursor condensed at $-155^{\circ} \mathrm{C}$, with focused electron irradiation under $15 \mathrm{kV}$ beam energy and $0.71 \mathrm{nA}$ beam current [54]. As shown in Figure 3 , the main result is an increase of four orders of magnitude in the growth rate by Cryo-FEBID, reaching values in the range of $10^{3} \mu \mathrm{C} / \mathrm{cm}^{2}$, similar to electron doses required for the exposure of resists in EBL with PMMA resist [2]. The condensate thickness was varied by Bresin et al. in the $75 \mathrm{~nm}$ to $300 \mathrm{~nm}$ range by tuning the GIS temperature, the GIS-substrate distance and the GIS valve opening time. The authors report that the Pt content (in at \%) is $14 \%$, similar to that obtained when using RT FEBID. The authors also showed strategies to achieve 3D structures by tailored multiple precursor-layer condensation and irradiation. In short, the results obtained were promising for the fast growth of $\mathrm{Pt}-\mathrm{C}$ structures by Cryo-FEBID. However, no particular application was discussed or targeted.

\subsection{W-C Deposits Grown by Cryo-FIBID}

Córdoba et al. have recently used 30-nm thick layers of $\mathrm{W}(\mathrm{CO})_{6}$ precursor condensed at $-100{ }^{\circ} \mathrm{C}$, with focused $\mathrm{Ga}^{+}$ion irradiation under $30 \mathrm{kV}$ beam energy and $10 \mathrm{pA}$ beam current [55]. As shown in Figure 4, such working conditions plus ion doses in the range of $50 \mu \mathrm{C} / \mathrm{cm}^{2}$ have been found favorable for obtaining homogeneous void-free W-C deposits. The edge roughness of deposits grown with the optimized dose, of the order of $10 \mathrm{~nm}$, can be related to the ion beam size as well as to mechanical instabilities and drifts caused by various noise sources, including the vibrations coming from the flow of the gaseous nitrogen required to cool the stage. The required ion dose is 600 times lower than that required to obtain equivalent deposits at RT FIBID. Such ultra-fast growth is of great interest for decreasing the process time. As an example, the 100 micrometric rectangles shown in Figure $4 \mathrm{~b}$ only required $85 \mathrm{~s}$ of $\mathrm{Ga}^{+}$irradiation, whereas the equivalent deposit grown by RT FIBID would take $14 \mathrm{~h}$. 


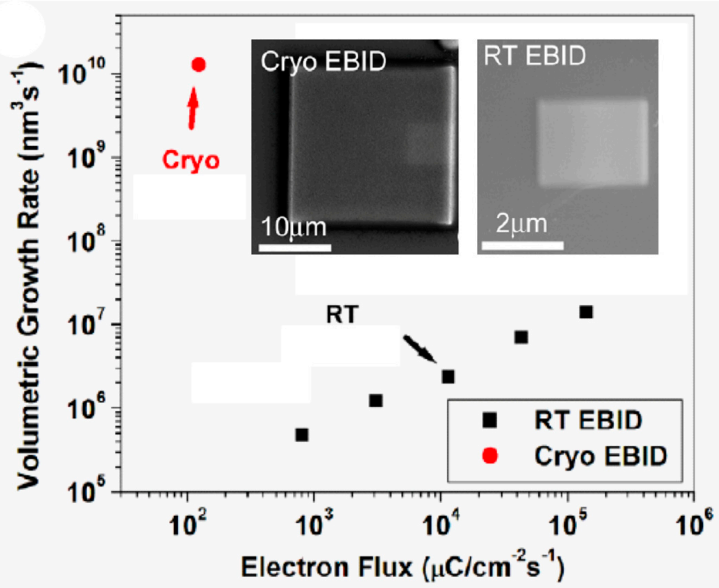

Figure 3. Growth rate enhancement of Pt-C deposits grown by Cryo-FEBID compared to those grown using RT FEBID. The inset shows SEM micrographs of the obtained deposits. Adapted and reprinted from Bresin et al., Nanotechnology 2013 [54].
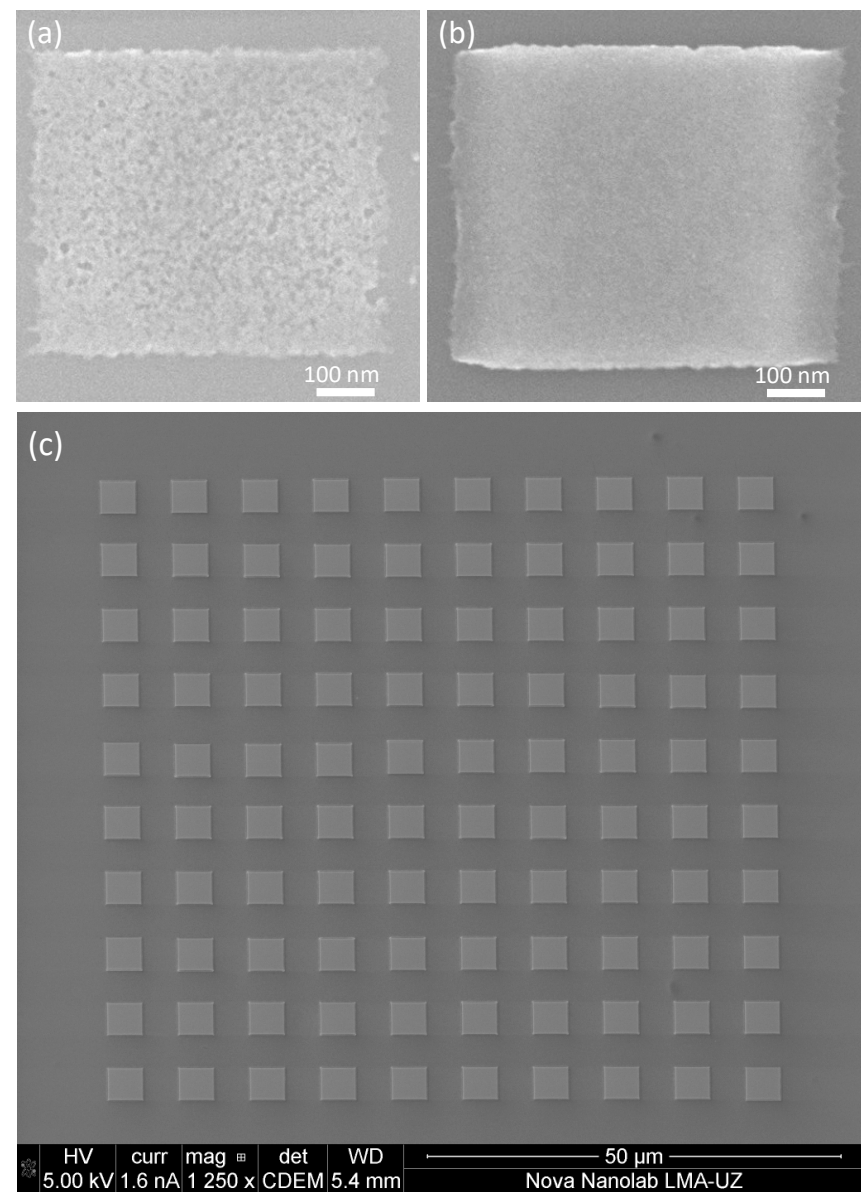

Figure 4. (a) SEM micrograph of a W-C 30-nm thick Cryo-deposit irradiated with a $4.21 \mu \mathrm{C} / \mathrm{cm}^{2}$ dose (unoptimized dose); (b) SEM micrograph of a W-C 30-nm thick Cryo-deposit irradiated with a 35.7 $\mu \mathrm{C} / \mathrm{cm}^{2}$ dose (optimized dose); (c) SEM micrograph of a W-C Cryo-deposit array, composed of 100 rectangles of $4 \mu \mathrm{m}^{2} \times 3.85 \mu \mathrm{m}^{2}$ in size, grown in a single $\mathrm{Ga}^{+}$irradiation exposure using an irradiation dose of $50 \mu \mathrm{C} / \mathrm{cm}^{2}$, amounting to a total irradiation time of $85 \mathrm{~s}$ (compared with $14 \mathrm{~h}$ using RT FIBID). Adapted and reprinted from Córdoba et al., Scientific Reports 2019 [55]. 
All the compositional analyses of the W-C Cryo-deposits, performed by EDX-STEM techniques, indicated a gradient of composition as a function of the deposit height. The amount of $\mathrm{W}$ is above $20 \%$ in the top half of the deposit, close to the surface, but decreases to below $10 \%$ in the bottom half of the deposit, near the substrate. In order to understand this behavior, simulations on $30 \mathrm{kV}$ $\mathrm{Ga}^{+}$irradiation at a normal incidence of a $30 \mathrm{~nm}$ thick $\mathrm{W}(\mathrm{CO})_{6}$ film on a silicon substrate have been performed using the SDTRIMSP code [56], which is based on TRIM [57,58] but allows for dynamics simulations, modelling ion-beam processes as a function of fluence while taking diffusion processes into account $[59,60]$. For the simulations in this work, the $\mathrm{KrC}$ potential has been used for interatomic interactions, the Oen-Robinson model for electronic stopping, and the Gauss-Mehler method with 16 pivots for integration. The surface binding energy is calculated using sbe $(i, j)=0.5\left(E s_{i}+E s_{j}\right)$, where sbe is the surface binding energy for the target of consideration, and $E s_{i}$ is the atomic surface binding energy and where the surface binding energy of atom $i$ is calculated for any combination of $\mathrm{Ga}, \mathrm{C}, \mathrm{O}, \mathrm{W}$ and Si [56]. The atomic densities of tungsten, carbon and oxygen have been considered identical to the bulk values, which may lead to a density of the precursor film above the experimental value. The diffusion of atoms has also been neglected as no experimental values were available for the experimental conditions of the current work. However, this process could be relevant for the diffusion of carbon and oxygen atoms under Ga irradiation in Cryo-FIBID, meaning that the surface concentrations of oxygen and carbon in the simulations might be overestimated and that of tungsten underestimated. In a previous study on the rare gas ion irradiation of polymer samples, including diffusion processes was essential for a correct modelling of the processes under ion irradiation [60,61].

In the current work, the simulated tungsten concentration of about $8 \%$ at a fluence of $4 \times 10^{14}$ ions $/ \mathrm{cm}^{2}$ (Figure 5), which is in the range of the optimized irradiation dose according to Córdoba et al. [55], is also lower than the experimental surface concentration of above $20 \%$, which gives an indication that diffusion processes and/or outgassing after the dissociation of the precursor molecules play a role but are not accounted for in the modelling. Although the $\mathrm{W}$ surface concentration starts to increase in the simulations with a fluence of $4 \times 10^{14}$ ions $/ \mathrm{cm}^{2}$ (Figure $5 \mathrm{~b}$ ), the tungsten surface concentration only starts to be significantly above the initial concentration of the precursor film for fluences above $10^{16}$ ions $/ \mathrm{cm}^{2}$ (see Figure A1 in Appendix A). For the fluence corresponding to experimental conditions, the Ga surface concentration is still low, with the maximum of the implantation profile being more or less at the $\mathrm{W}(\mathrm{CO})_{6} / \mathrm{Si}$ interface (Figure $5 \mathrm{a}$ ). For higher fluences in the range of $10^{16}$ ions $/ \mathrm{cm}^{2}$, the Ga concentration starts approaching the percent range at the sample surface and a peak concentration of about $10 \%$ range (see Appendix A). For the lower fluences, the loss of carbon is dominant while at higher fluences the loss of oxygen prevails. Partial sputtering yields are almost constant, with 0.06 for $\mathrm{W}, 0.92$ for $\mathrm{C}$ and 1.16 for $\mathrm{O}$.

Since the main application of W-C FIBID deposits is based on their metallic character, it is important to investigate whether the W-C deposits grown by Cryo-FIBID exhibit it. As shown in Figure 6, these deposits display metal behavior and can be used as metallic interconnects. The observed resistivity, $800 \mu \Omega \mathrm{cm}$, is slightly higher than that in the corresponding W-C deposits grown by RT FIBID, 300 $\mu \Omega \mathrm{cm}$, which is to be expected due to the larger metal content in the latter [62,63]. The value of 300 $\mu \Omega \mathrm{cm}$ for room-temperature FIBID is just an average of results found in the literature. However, depending on the growth parameters, the deposit thickness, the vacuum conditions or the state of the precursor material, amongst others, it ranges from $100 \mu \Omega \mathrm{cm}$ to $3000 \mu \Omega \mathrm{cm}[27,62,64-66]$. Similarly, the resistivity of other conductive FIBID deposits, such as $\mathrm{Pt}-\mathrm{C}$, also spans a broad range (from 700 $\mu \Omega \mathrm{cm}$ to $10^{8} \mu \Omega \mathrm{cm}$ ) given its strong dependence on the deposit thickness [67]. On the other hand, W-C deposits grown by RT FEBID show resistivity values at least ten times higher than RT FIBID [68]. 

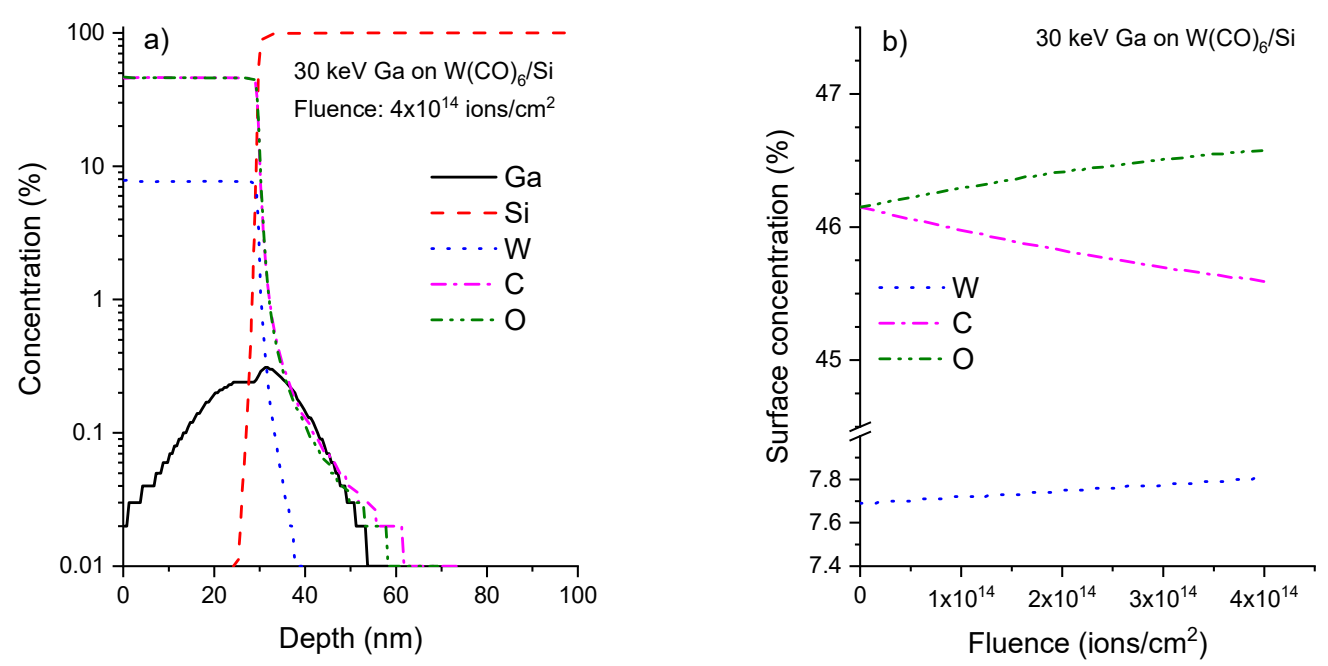

Figure 5. (a) Theoretical composition as a function of depth for Cryo-FIBID W-C deposits according to the calculations reported in the main text for a fluence of $4 \times 10^{14}$ ions $/ \mathrm{cm}^{2}$; (b) Surface composition as a function of fluence for the same modelling conditions as for (a).

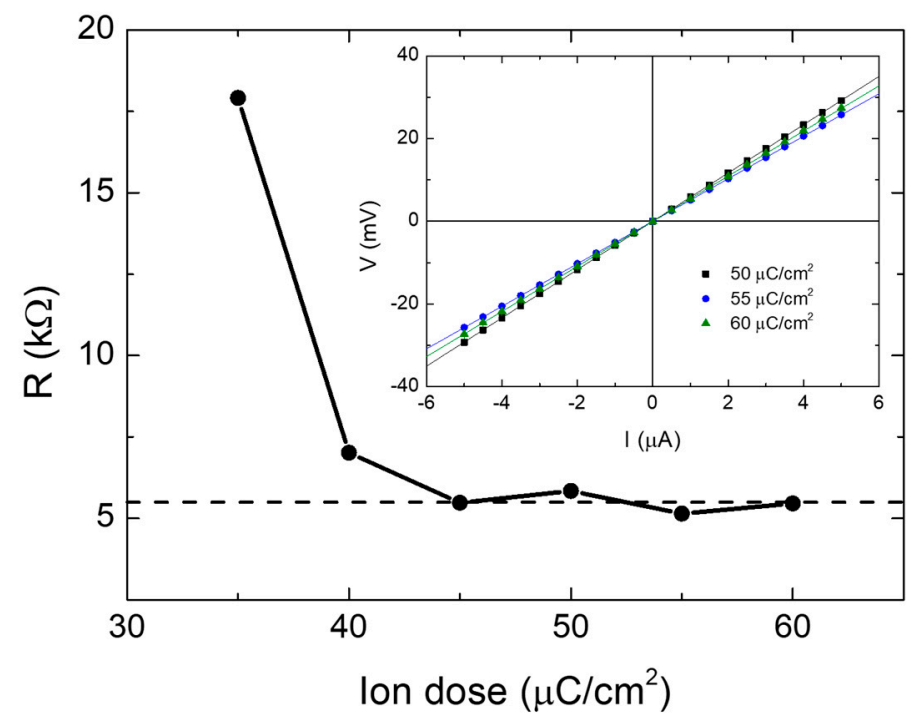

Figure 6. Electrical resistance as a function of the $\mathrm{Ga}^{+}$irradiation dose in $\mathrm{W}-\mathrm{C}$ deposits grown by Cryo-FIBID, suggesting that an optimized dose to achieve the lowest resistance value occurs in the 45 to $60 \mu \mathrm{C} / \mathrm{cm}^{2}$ range. The current-versus-voltage measurements shown in the inset are compatible with metallic behavior. Adapted and reprinted from Córdoba et al., Scientific Reports 2019 [55].

Regarding the lateral resolution of Cryo-FEBID, Bresin et al. showed that $40 \mathrm{~nm}$ is achievable with a 70-nm thick condensed layer [54]. The lateral resolution worsens to $140 \mathrm{~nm}$ if a 280-nm thick condensed layer is used. On the other hand, Córdoba et al. have shown a 38-nm lateral resolution in Cryo-FIBID with a 30-nm thick condensed layer [55]. The proximity effect observed in that work is surprisingly small, with two nanowires separated by a $7 \mathrm{~nm}$ gap. The application of Cryo-FIBID for the fabrication of highly-dense nano-objects is thus very promising.

It is also worth mentioning that Cryo-FEBID and Cryo-FIBID processes can be repeated multiple times on the same sample in order to produce 3D structures, or to grow various materials or to increase the thickness of the deposited material, widening the range of applications [54]. 


\section{Discussion and Conclusions}

The use of cryogenic conditions implies the integration of a cryogenic module in the equipment, spending a few s or minutes lowering (and subsequently increasing) the temperature and coping with effects, such as temperature-induced drifts in the mechanical parts of the equipment. The outstanding time saving of FEBID and FIBID processes with condensed precursor layers is one benefit that outweighs the inconveniences of working under cryogenic conditions. In the case of Pt-Cryo-FEBID, the growth rate has been found to increase by about four orders of magnitude compared to the equivalent RT process [54], whereas in the case of W-Cryo-FIBID, it is enhanced about 600 times [55]. This will definitely have a great impact in the total process time when large areas need to be patterned, as shown in Figure 4.

In order to put the obtained results in context, the area dose required in the main charged-particle-based nanolithography techniques is displayed in Figure 7. Such lithography techniques can be classified depending on whether they are single-step resist-free or multi-step resist-based. The most common resist-based nanolithography technique using charge particles is EBL. Processes based on PMMA resist are widespread due to the achievement of high resolution requiring moderate electron doses, in the range of a few-hundred $\mu \mathrm{C} / \mathrm{cm}^{2}$ [2]. Faster EBL processes, with doses lower than $100 \mu \mathrm{C} / \mathrm{cm}^{2}$, are possible using specific resists such as HSQ (hydrogen silsesquioxane) [2]. Even faster resist-based processes (a few $\mu \mathrm{C} / \mathrm{cm}^{2}$ ) have been described by Focused Ion Beam Lithography (FIBL) using PMMA, HSQ or fullerene-based resists with $\mathrm{He}^{+}$irradiation exposure [69-71] and SAL 601 resist with $\mathrm{Ga}^{+}$irradiation exposure [72]. After resist exposure, a few more steps have to be followed, typically resist development, metal evaporation and lift-off, which leads to long processing times. In some cases, resist residues are detrimental and additional steps are required. However, single-step resist-free nanolithography processes have the advantage of being simple if the right material can be produced. In fact, great effort has been made in recent years to obtain functional materials by FEBID and FIBID, which can include a purification step $[73,74]$. In most FEBID and FIBID processes, the required charge dose is high, giving rise to long processing times with the exception of $\mathrm{Pt}$ deposits by FIBID, which require an irradiation dose of around $10^{3} \mu \mathrm{C} / \mathrm{cm}^{2}$ [20]. The use of FIBID implies ion implantation and ion-induced damage, which can be detrimental in certain applications. Thus, the use of FEBID and FIBID at room temperature presents limitations in speed or causes damage that hampers a broader use. In Figure 7, another example of a single-step resist-free charge-based nanolithography technique is included, that of the formation of ultra-thin carbon membranes from the exposure of self-assembled monolayers (SAM), which require at least $850 \mu \mathrm{C} / \mathrm{cm}^{2}$ [75]. As shown in Figure 7, the use of Cryo-FEBID and Cryo-FIBID opens new opportunities due to the lower area charge dose required. In the case of Cryo-FEBID, if this technique is able to demonstrate material functionality, it can significantly decrease the processing times of RT FEBID. In the case of Cryo-FIBID, the two main problems linked to RT FIBID can be minimized. First, the processing time is substantially decreased compared to the rest of existing single-step resist-free methods, given the required low dose of $50 \mu \mathrm{C} / \mathrm{cm}^{2}$ [55]. Secondly, the ion implantation and ion-induced damage can to a large extent be suppressed. Cryo-FIBID has shown material functionality, leading to metallic W-C deposits used to contact a semiconducting nanowire for the investigation of its electrical properties [55]. 


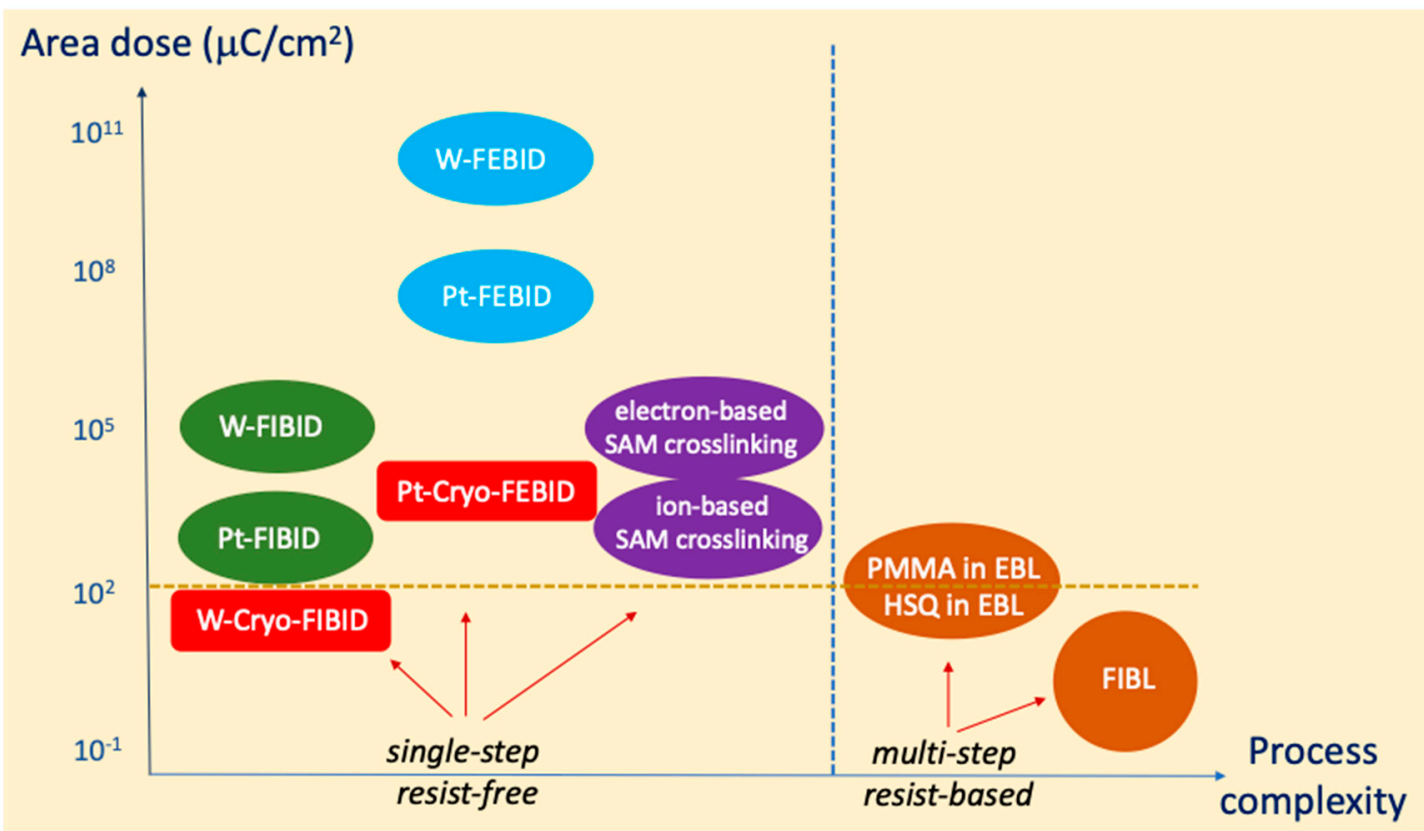

Figure 7. Comparison of charge-particle-based lithography techniques in terms of the required charge dose per area and the process complexity. The single-step or multi-step character of the technique is considered a means to classify it as a process with less or more complexity, respectively. Cryo-FIBID requires the lowest charge dose amongst the single-step techniques.

Following the previous discussion, it is fair to anticipate the potential applications of Cryo-FEBID and Cryo-FIBID. In the field of circuit edit, Cryo-FIBID seems a promising technique to replace RT FIBID given the existing demonstration of metallic W-C Cryo-deposits requiring a very low charge dose [55]. For mask repair, both, Cryo-FEBID and Cryo-FIBID, could play a relevant role in decreasing the processing time if the right material deposition is demonstrated in the future. Besides, Cryo-FEBID has been shown to be a viable technique that would span the range of etching processes available [51]. However, we would like to point out that cryogenic processes bring about unavoidable thermal drifts, which could limit the implementation of the technique in the most demanding high-resolution applications.

Moreover, Cryo-FIBID can be used straightforwardly to place metallic contacts for the investigation of the electrical properties of nano-objects with minimized ion-induced damage. Thus, one can anticipate that research of 2D, epitaxial oxides, very-thin nanowires and topological insulators could benefit from it. It could even be applied to other materials such as organic layers if these can maintain their properties when submitted to the cooling and heating process. More generally, given that the low charge doses required in Cryo-FEBID and Cryo-FIBID are comparable to those used in multi-step resist-based processes, it is not unreasonable to consider these techniques for large-scale nanopatterning processes. Thus, the growth of large-scale metal contacts on resist-sensitive materials, or the growth of large-scale unique functional materials by FEBID and FIBID, or the growth of large-scale nanoscale hard masks, can be obtained from these techniques. For example, large-area patterning, in the $\mathrm{cm}^{2}$ range, has been developed for EBL. For that, advanced stages relying on laser interferometry are used to optimize stitching. Nevertheless, given that Cryo-FIBID requires a homogeneous condensed layer, new designs of gas injection systems would prove useful for precursor delivery in large areas.

Furthermore, the use of other FIB sources different from $\mathrm{Ga}^{+}\left(\right.$such as $\mathrm{He}^{+}, \mathrm{Ne}^{+}, \mathrm{Xe}^{+}$, etc.) provides another opportunity to enlarge the applicability of the Cryo-FIBID technique [3]. Depending on the type of ion and its accelerating voltage and working current, access to a wide range of irradiation depth, resolution, process time, and material functionality exists. 
To sum up, in the present article we compare the performance of focused beam-induced deposition techniques under cryogenic temperatures compared to conventional room-temperature processes. With required area charge doses a few orders of magnitude lower than conventional RT FEBID and FIBID, Cryo-FEBID and Cryo-FIBID show the main advantage of the gain in process speed. Cryo-FIBID is found to be very promising, given the demonstration of metallic W-C deposits with an irradiation dose of around $50 \mu \mathrm{C} / \mathrm{cm}^{2}$. These low ion doses pave the way for the application of Cryo-FIBID on ion-sensitive materials, which usually become damaged with the conventional irradiation doses used in RT FIBID. Other nanopatterning strategies based on Cryo-FEBID and Cryo-FIBID, and competitive with respect to well-established multi-step resist-based approaches, are expected to come in the future.

Author Contributions: J.M.D.T. devised this review article and wrote the first version of the manuscript. P.O., R.C. and P.P. contributed to the figures, discussed the content and agreed on the final version of the manuscript. P.P. performed the simulations included in Figure 5 and Appendix A.

Funding: This research was funded by the Spanish Ministry of Science, grant numbers MAT2017-82970-C2-2-R and MAT2018-102627-T, and by the Aragon Government (Construyendo Europa desde Aragón), grant numbers E13_17R and LMP33_18, with the European Social Fund.

Acknowledgments: Fruitful discussions on the topic with Teobaldo E. Torres and Stefan Strohauer are acknowledged.

Conflicts of Interest: The authors declare no conflict of interest. The funders had no role in the design of the study; in the collection, analyses, or interpretation of data; in the writing of the manuscript, or in the decision to publish the results.

\section{Appendix A}
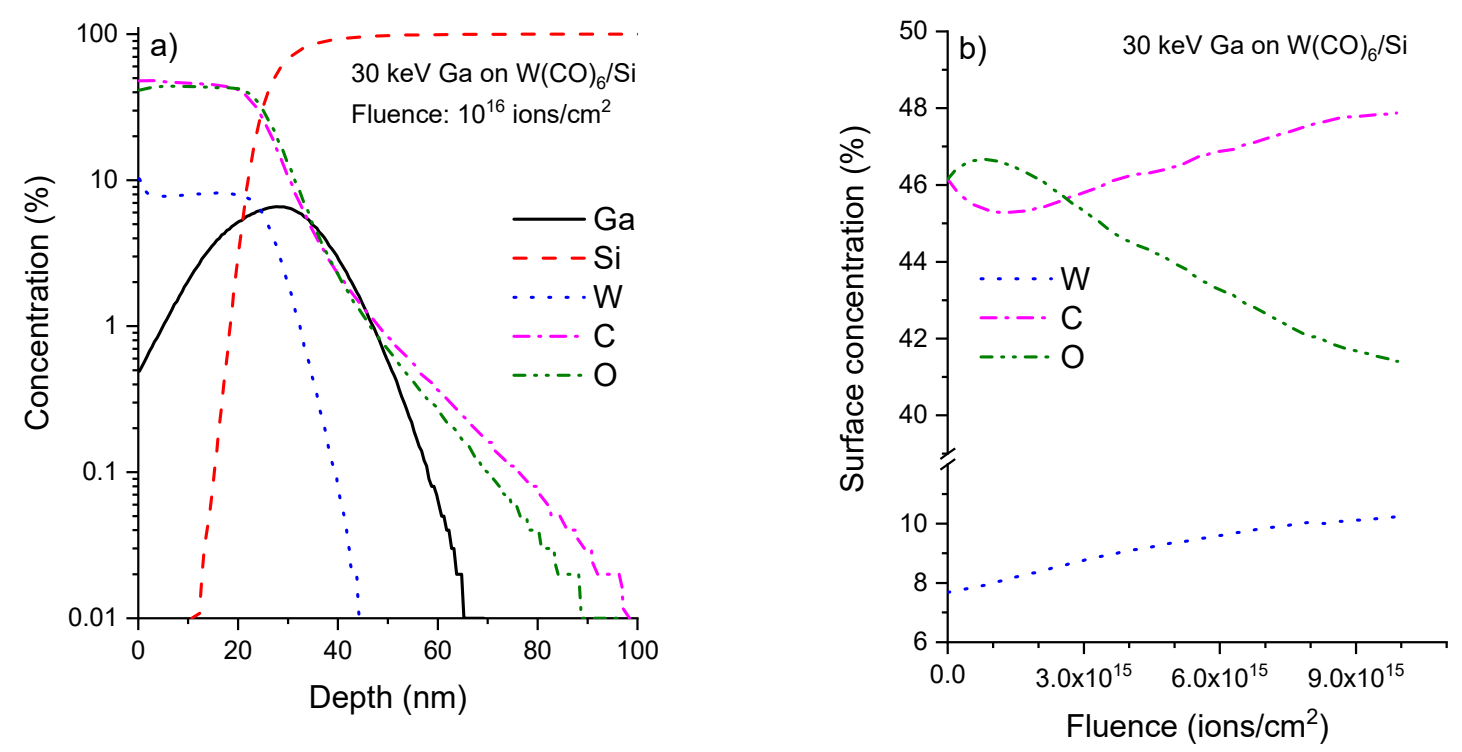

Figure A1. (a) Theoretical composition as a function of depth for Cryo-FIBID W-C deposits according to the calculations reported in the main text for a fluence of $1 \times 10^{16}$ ions $/ \mathrm{cm}^{2}$; (b) Surface composition as a function of fluence for the same modelling conditions than for (a).

\section{References}

1. Biswas, A.; Bayer, I.S.; Biris, A.S.; Wang, T.; Dervishi, E.; Faupel, F. Advances in top-down and bottom-up surface nanofabrication: Techniques, applications \& future prospects. Adv. Colloid Interface Sci. 2012, 170, 2-27. [PubMed]

2. Grigorescu, A.E.; Hagen, C.W. Resists for sub-20-nm electron beam lithography with a focus on HSQ: State of the art. Nanotechnology 2009, 20, 292001. [CrossRef] [PubMed] 
3. Bruchhaus, L.; Mazarov, P.; Bischoff, L.; Gierak, J.; Wieck, A.D.; Hövel, H. Comparison of technologies for nano device prototyping with a special focus on ion beams: A review. Appl. Phys. Rev. 2017, 4, 011302. [CrossRef]

4. Tseng, A.A. Recent developments in nanofabrication using focused ion beams. Small 2005, 1, 924-939. [CrossRef]

5. Mohiuddin, T. Focused ion beam (FIB) circuit edit. Electron. Device Fail. Anal. 2014, 16, 20-23.

6. Reyntjens, S.; Puers, R. A review of focused ion beam applications in microsystems technology. J. Micromech. Microeng. 2001, 11, 287-300. [CrossRef]

7. Giannuzzi, L.A.; Stevie, F.A. A review of focused ion beam milling techniques for TEM specimen preparation. Micron 1999, 30, 197-204. [CrossRef]

8. Randolph, S.J.; Fowlkes, J.D.; Rack, P.D. Focused, Nanoscale Electron-Beam-Induced Deposition and Etching. Crit. Rev. Solid State Mater. Sci. 2006, 31, 55-89. [CrossRef]

9. Utke, I.; Hoffmann, P.; Melngailis, J. Gas-Assisted Focused Electron Beam and Ion Beam Processing and Fabrication. J. Vac. Sci. Technol. B Microelectron. Nanom. Struct. 2008, 26, 1197. [CrossRef]

10. Van Dorp, W.F.; Hagen, C.W. A critical literature review of focused electron beam induced deposition. J. Appl. Phys. 2008, 104, 081301. [CrossRef]

11. Huth, M.; Porrati, F.; Schwalb, C.; Winhold, M.; Sachser, R.; Dukic, M.; Adams, J.; Fantner, G. Focused electron beam induced deposition: A perspective. Beilstein J. Nanotechnol. 2012, 3, 597-619. [CrossRef] [PubMed]

12. Winkler, R.; Geier, B.; Plank, H. Spatial chemistry evolution during focused electron beam-induced deposition: Origins and workarounds. Appl. Phys. A Mater. Sci. Process. 2014, 117, 1675-1688. [CrossRef]

13. Alkemade, P.F.A.; Miro, H. Focused helium-ion-beam-induced deposition. Appl. Phys. A Mater. Sci. Process. 2014, 117, 1727-1747. [CrossRef]

14. Fowlkes, J.D.; Randolph, S.J.; Rack, P.D. Growth and Simulation of High-Aspect Ratio Nanopillars by Primary and Secondary Electron-Induced Deposition. J. Vac. Sci. Technol. B 2005, 23, 2825-2832. [CrossRef]

15. Smith, D.A.; Fowlkes, J.D.; Rack, P.D. A nanoscale three-dimensional Monte Carlo simulation of electron-beam-induced deposition with gas dynamics. Nanotechnology 2007, 18, 265308. [CrossRef]

16. Arnold, G.; Timilsina, R.; Fowlkes, J.; Orthacker, A.; Kothleitner, G.; Rack, P.D.; Plank, H. Fundamental resolution limits during electron-induced direct-write synthesis. ACS Appl. Mater. Interfaces 2014, 6, 7380-7387. [CrossRef]

17. Schmied, R.; Fowlkes, J.D.; Winkler, R.; Rack, P.D.; Plank, H. Fundamental edge broadening effects during focused electron beam induced nanosynthesis. Beilstein J. Nanotechnol. 2015, 6, 462-471. [CrossRef]

18. De Teresa, J.M.; Córdoba, R. Arrays of Densely-Packed Isolated Nanowires by Focused Beam Induced Deposition Plus Ar ${ }^{+}$Milling. ACS Nano 2014, 8, 3788-3795. [CrossRef]

19. Kohama, K.; Iijima, T.; Hayashida, M.; Ogawa, S. Tungsten-based pillar deposition by helium ion microscope and beam-induced substrate damage. J. Vac. Sci. Technol. B Nanotechnol. Microelectron. Mater. Process. Meas. Phenom. 2013, 31, 031802. [CrossRef]

20. De Teresa, J.M.; Córdoba, R.; Fernández-Pacheco, A.; Montero, O.; Strichovanec, P.; Ibarra, M.R. Origin of the difference in the resistivity of as-grown focused-ion- and focused-electron-beam-induced Pt nanodeposits. J. Nanomater. 2009, 2009, 936863. [CrossRef]

21. Borschel, C.; Ronning, C. Ion beam irradiation of nanostructures-A 3D Monte Carlo simulation code. Nucl. Instrum. Methods Phys. Res. Sect. B Beam Interact. Mater. At. 2011, 269, 2133-2138. [CrossRef]

22. Schilling, A.; Adams, T.; Bowman, R.M.; Gregg, J.M. Strategies for gallium removal after focused ion beam patterning of ferroelectric oxide nanostructures. Nanotechnology 2007, 18, 035301. [CrossRef] [PubMed]

23. Friedensen, S.; Mlack, J.T.; Drndić, M. Materials analysis and focused ion beam nanofabrication of topological insulator $\mathrm{Bi}_{2} \mathrm{Se}_{3}$. Sci. Rep. 2017, 7, 13466. [CrossRef] [PubMed]

24. Drezner, Y.; Fishman, D.; Greenzweig, Y.; Raveh, A. Characterization of damage induced by FIB etch and tungsten deposition in high aspect ratio vias. J. Vac. Sci. Technol. B Nanotechnol. Microelectron. Mater. Process. Meas. Phenom. 2011, 29, 011026. [CrossRef]

25. Matsui, S.; Ochiai, Y. Focused ion beam applications to solid state devices. Nanotechnology 1996, 7, $247-258$. [CrossRef]

26. Castagné, M.; Benfedda, M.; Lahimer, S.; Falgayrettes, P.; Fillard, J.P. Near field optical behaviour of C supertips. Ultramicroscopy 1999, 76, 187-194. [CrossRef] 
27. Peinado, P.; Sangiao, S.; De Teresa, J.M. Focused Electron and Ion Beam Induced Deposition on Flexible and Transparent Polycarbonate Substrates. ACS Nano 2015, 9, 6139-6146. [CrossRef] [PubMed]

28. Pablo-Navarro, J.; Sangiao, S.; Magen, C.; de Teresa, J.M. Diameter modulation of 3D nanostructures in Focused Electron Beam Induced Deposition using local electric fields and beam defocus. Nanotechnology 2019, 30, 505302. [CrossRef] [PubMed]

29. Gannon, T.J.; Gu, G.; Casey, J.D.; Huynh, C.; Bassom, N.; Antoniou, N. Focused ion beam induced deposition of low-resistivity copper material. J. Vac. Sci. Technol. B Microelectron. Nanom. Struct. 2004, 22, 3000-3003. [CrossRef]

30. Yasaka, A.; Aramaki, F.; Kozakai, T.; Matsuda, O. Nanoscale imaging, material removal and deposition for fabrication of cutting-edge semiconductor devices ion-beam-based photomask defect repair technology. Hitachi Rev. 2016, 65, 71-75.

31. Gonzalez, C.M.; Slingenbergh, W.; Timilsina, R.; Noh, J.-H.; Stanford, M.G.; Lewis, B.B.; Klein, K.L.; Liang, T.; Fowlkes, J.D.; Rack, P.D. Evaluation of mask repair strategies via focused electron, helium, and neon beam induced processing for EUV applications. Int. Soc. Opt. Photonics 2014, 9048, 90480M.

32. Cronin, S.B.; Lin, Y.; Rabin, O.; Black, M.R. Making electrical contacts to nanowires. Nanotechnology 2002, 13, 653-658. [CrossRef]

33. Hiley, C.I.; Scanlon, D.O.; Sokol, A.A.; Woodley, S.M.; Ganose, A.M.; Sangiao, S.; De Teresa, J.M.; Manuel, P.; Khalyavin, D.D.; Walker, M.; et al. Antiferromagnetism at T $>500 \mathrm{~K}$ in the layered hexagonal ruthenate $\mathrm{SrRu}_{2} \mathrm{O}_{6}$. Phys. Rev. B Condens. Matter Mater. Phys. 2015, 92, 104413. [CrossRef]

34. Moczała, M.; Kwoka, K.; Piasecki, T.; Kunicki, P.; Sierakowski, A.; Gotszalk, T. Fabrication and characterization of micromechanical bridges with strain sensors deposited using focused electron beam induced technology. Microelectron. Eng. 2017, 176, 111-115. [CrossRef]

35. Schwalb, C.H.; Grimm, C.; Baranowski, M.; Sachser, R.; Porrati, F.; Reith, H.; Das, P.; Müller, J.; Völklein, F.; Kaya, A.; et al. A tunable strain sensor using nanogranular metals. Sensors 2010, 10, 9847-9856. [CrossRef] [PubMed]

36. Belova, L.M.; Hellwig, O.; Dobisz, E.; Dan Dahlberg, E. Rapid preparation of electron beam induced deposition Co magnetic force microscopy tips with $10 \mathrm{~nm}$ spatial resolution. Rev. Sci. Instrum. 2012, 83, 093711. [CrossRef] [PubMed]

37. Utke, I.; Hoffmann, P.; Berger, R.; Scandella, L. High-resolution magnetic Co supertips grown by a focused electron beam. Appl. Phys. Lett. 2002, 80, 4792-4794. [CrossRef]

38. Gavagnin, M.; Wanzenboeck, H.D.; Wachter, S.; Shawrav, M.M.; Persson, A.; Gunnarsson, K.; Svedlindh, P.; Stöger-Pollach, M.; Bertagnolli, E. Free-standing magnetic nanopillars for 3D nanomagnet logic. ACS Appl. Mater. Interfaces 2014, 6, 20254-20260. [CrossRef]

39. Höflich, K.; Yang, R.B.; Berger, A.; Leuchs, G.; Christiansen, S. The Direct Writing of Plasmonic Gold Nanostructures by Electron-Beam-Induced Deposition. Adv. Mater. 2011, 23, 2657-2661. [CrossRef]

40. Winkler, R.; Schmidt, F.P.; Haselmann, U.; Fowlkes, J.D.; Lewis, B.B.; Kothleitner, G.; Rack, P.D.; Plank, H. Direct-Write 3D Nanoprinting of Plasmonic Structures. ACS Appl. Mater. Interfaces 2017, 9, 8233-8240. [CrossRef]

41. Graells, S.; Aćimović, S.; Volpe, G.; Quidant, R. Direct growth of optical antennas using e-beam-induced gold deposition. Plasmonics 2010, 5, 135-139. [CrossRef]

42. Belić, D.; Shawrav, M.M.; Gavagnin, M.; Stöger-Pollach, M.; Wanzenboeck, H.D.; Bertagnolli, E. Direct-write deposition and focused-electron-beam-induced purification of gold nanostructures. ACS Appl. Mater. Interfaces 2015, 7, 2467-2479. [CrossRef] [PubMed]

43. Esposito, M.; Tasco, V.; Cuscunà, M.; Todisco, F.; Benedetti, A.; Tarantini, I.; De Giorgi, M.; Sanvitto, D.; Passaseo, A. Nanoscale 3D chiral plasmonic helices with circular dichroism at visible frequencies. ACS Photonics 2015, 2, 105-114. [CrossRef]

44. Guillamón, I.; Córdoba, R.; Sesé, J.; De Teresa, J.M.; Ibarra, M.R.; Vieira, S.; Suderow, H. Enhancement of long-range correlations in a 2D vortex lattice by an incommensurate $1 \mathrm{D}$ disorder potential. Nat. Phys. 2014, 10, 851-856. [CrossRef]

45. Sadki, E.S.; Ooi, S.; Hirata, K. Focused-ion-beam-induced deposition of superconducting nanowires. Appl. Phys. Lett. 2004, 85, 6206-6208. [CrossRef]

46. Han, A.; Kuan, A.; Golovchenko, J.; Branton, D. Nanopatterning on nonplanar and fragile substrates with ice resists. Nano Lett. 2012, 12, 1018-1021. [CrossRef] 
47. Tiddi, W.; Elsukova, A.; Le, H.T.; Liu, P.; Beleggia, M.; Han, A. Organic Ice Resists. Nano Lett. 2017, 17, 7886-7891. [CrossRef]

48. Tiddi, W.; Elsukova, A.; Beleggia, M.; Han, A. Organic ice resists for 3D electron-beam processing: Instrumentation and operation. Microelectron. Eng. 2018, 192, 38-43. [CrossRef]

49. Desbois, G.; Urai, J.L.; Burkhardt, C.; Drury, M.R.; Hayles, M.; Humbel, B. Cryogenic vitrification and 3D serial sectioning using high resolution cryo-FIB SEM technology for brine-filled grain boundaries in halite: First results. Geofluids 2008, 8, 60-72. [CrossRef]

50. Parmenter, C.D.J.; Fay, M.W.; Hartfield, C.; Eltaher, H.M. Making the Practically Impossible "Merely Difficult"-Cryogenic FIB Lift-Out for “Damage Free" Soft Matter Imaging. Microsc. Res. Tech. 2016, 79, 298. [CrossRef]

51. Martin, A.A.; Toth, M. Cryogenic Electron Beam Induced Chemical Etching. ACS Appl. Mater. Interfaces 2014, 6, 18457-18460. [CrossRef] [PubMed]

52. Funsten, H.O.; Boring, J.W.; Johnson, R.E.; Brown, W.L. Low-temperature beam-induced deposition of thin tin films. J. Appl. Phys. 1992, 71, 1475-1484. [CrossRef]

53. Bresin, M.; Thiel, B.L.; Toth, M.; Dunn, K.A.; Toth, M. Focused electron beam-induced deposition at cryogenic temperatures. J. Mater. Res. 2011, 26, 357-364. [CrossRef]

54. Bresin, M.; Toth, M.; Dunn, K. A Direct-write 3D nanolithography at cryogenic temperatures. Nanotechnology 2013, 24, 035301. [CrossRef] [PubMed]

55. Córdoba, R.; Orús, P.; Strohauer, S.; Torres, T.E.; De Teresa, J.M. Ultra-fast direct growth of metallic microand nano-structures by focused ion beam irradiation. Sci. Rep. 2019, 9, 14076. [CrossRef]

56. Mutzke, A.; Schneider, R.; Eckstein, W.; Dohmen, R. SDTrimSP Technical Report Version 5.00; Max-Planck-Institut für Plasmaphysik: Garching, Germany, 2011; IPP 12/8.

57. Biersack, J.P.; Haggmark, L.G. A Monte Carlo program for the transport of energetic ions in amorphous targets. Nucl. Instrum. Methods 1980, 174, 257. [CrossRef]

58. Eckstein, W.; Möller, W. Computer simulations of preferential sputtering. Nucl. Instrum. Methods Phys. Res. Sect. B Beam Interact. Mater. At. 1985, 7, 727. [CrossRef]

59. Mutzke, A.; Eckstein, W. Ion fluence dependence of the Si sputtering yield by noble gas ion bombardment. Nucl. Instrum. Methods Phys. Res. Sect. B Beam Interact. Mater. At. 2008, 266, 872-876. [CrossRef]

60. Rzeznik, L.; Fleming, Y.; Wirtz, T.; Philipp, P. Experimental and simulation-based investigation of $\mathrm{He}, \mathrm{Ne}$ and Ar irradiation of polymers for ion microscopy. Beilstein J. Nanotechnol. 2016, 7, 1113-1128. [CrossRef]

61. Philipp, P.; Rzeznik, L.; Wirtz, T. Numerical investigation of depth profiling capabilities of helium and neon ions in ion microscopy. Beilstein J. Nanotechnol. 2016, 7, 1749-1760. [CrossRef]

62. Li, W.; Fenton, J.C.; Wang, Y.; Mccomb, D.W.; Warburton, P.A. Tunability of the superconductivity of tungsten films grown by focused-ion-beam direct writing. J. Appl. Phys. 2008, 104, 093913. [CrossRef]

63. Guillamón, I.; Suderow, H.; Vieira, S.; Fernández-Pacheco, A.; Sesé, J.; Córdoba, R.; De Teresa, J.M.; Ibarra, M.R. Nanoscale superconducting properties of amorphous W-based deposits grown with a focused-ion-beam. New J. Phys. 2008, 10, 93005. [CrossRef]

64. Spoddig, D.; Schindler, K.; Rödiger, P.; Barzola-Quiquia, J.; Fritsch, K.; Mulders, H.; Esquinazi, P. Transport properties and growth parameters of PdC and WC nanowires prepared in a dual-beam microscope. Nanotechnology 2007, 18, 495202. [CrossRef] [PubMed]

65. Langfischer, H.; Basnar, B.; Hutter, H.; Bertagnolli, E. Evolution of tungsten film deposition induced by focused ion beam. J. Vac. Sci. Technol. A Vac. Surf. Film. 2002, 20, 1408. [CrossRef]

66. Mongillo, M.; Jansen, L.; Audoit, G.; Berthier, R.; Cooper, D. Electronic Transport on W-Rich Films Deposited by Focused Ion Beam. J. Supercond. Nov. Magn. 2017, 30, 2261-2270. [CrossRef]

67. Fernández-Pacheco, A.; De Teresa, J.M.; Córdoba, R.; Ibarra, M.R. Metal-insulator transition in Pt-C nanowires grown by focused-ion-beam- induced deposition. Phys. Rev. B Condens. Matter Mater. Phys. 2009, 79, 174204. [CrossRef]

68. Huth, M.; Klingenberger, D.; Grimm, C.; Porrati, F.; Sachser, R. Conductance regimes of W-based granular metals prepared by electron beam induced deposition. New J. Phys. 2009, 11, 033032. [CrossRef]

69. Winston, D.; Cord, B.M.; Ming, B.; Bell, D.C.; Dinatale, W.F.; Stern, L.A.; Vladar, A.E.; Postek, M.T.; Mondol, M.K.; Yang, J.K.W.; et al. Scanning-helium-ion-beam lithography with hydrogen silsesquioxane resist. J. Vac. Sci. Technol. B Microelectron. Nanom. Struct. 2009, 27, 2702-2706. [CrossRef] 
70. Hlawacek, G.; Gölzhäuser, A. (Eds.) Helium Ion Microscopy; Springer International Publishing: Cham, Switzerland, 2016; pp. 395-414.

71. Shi, X.; Prewett, P.; Huq, E.; Bagnall, D.M.; Robinson, A.P.G.; Boden, S.A. Helium ion beam lithography on fullerene molecular resists for sub-10 nm patterning. Microelectron. Eng. 2016, 155, 74-78. [CrossRef]

72. Hartney, M.A. Surface imaging of focused ion-beam exposed resists. J. Vac. Sci. Technol. B Microelectron. Nanom. Struct. 1991, 9, 3432. [CrossRef]

73. Botman, A.; Mulders, J.J.L.; Hagen, C.W. Creating pure nanostructures from electron-beam-induced deposition using purification techniques: A technology perspective. Nanotechnology 2009, 20, 372001. [CrossRef] [PubMed]

74. Pablo-Navarro, J.; Magén, C.; de Teresa, J.M. Purified and Crystalline Three-Dimensional Electron-Beam-Induced Deposits: The Successful Case of Cobalt for High-Performance Magnetic Nanowires. ACS Appl. Nano Mater. 2018, 1, 38-46. [CrossRef]

75. Zhang, X.; Vieker, H.; Beyer, A.; Gölzhäuser, A. Fabrication of carbon nanomembranes by helium ion beam lithography. Beilstein J. Nanotechnol. 2014, 5, 188-194. [CrossRef] [PubMed]

(C) 2019 by the authors. Licensee MDPI, Basel, Switzerland. This article is an open access article distributed under the terms and conditions of the Creative Commons Attribution (CC BY) license (http://creativecommons.org/licenses/by/4.0/). 